\title{
The Preparation of Some Benzothiazole Polymers and the Study of their Electrical Conductivity Properties
}

\author{
Asaad Faisal Khattab ${ }^{*}$, Haitham Ahmed Ayoob², Laith Mohammed Al Taan \\ ${ }^{1}$ Chemistry Department, College of Science, University of Mosul, Mosul, Iraq \\ ${ }^{2,3}$ Physics Department, College of Science, University of Mosul, Mosul, Iraq \\ E-mail: ${ }^{1 *}$ asaadfaisalkhattab@uomosul.edu.iq. ${ }^{2}$ haithamahmed1950@gmail.com ${ }^{3}$ laithaltaan@uomosul.edu.iq
}

(Received April 21, 2020; Accepted July 22, 2020; Available online December 01, 2020)

DOI: 10.33899/edusj.2020.126945.1066, (C) 2020, College of Education for Pure Science, University of Mosul.

This is an open access article under the CC BY 4.0 license (http://creativecommons.org/licenses/by/4.0/).

\begin{abstract}
:
As the conjugated polymers are doped with some electron donor or acceptor dopants, their electrical conductivity increased thoroughly to about $10^{-6} \Omega^{-1} \cdot \mathrm{cm}^{-1}$. The doping of the polymers may give an $\mathrm{n}$ or $\mathrm{p}$ semiconductor characteristic according to the types of the dopants that are used. Within the frame of this work, four types of conjugated polymers with benzothiazole as a major moiety in their backbone have been prepared. The prepared monomers and polymers have been characterized by FTIR spectroscopy. Elemental analysis of the polymers $(\mathrm{CHN})$ demonstrates their chemical structure while the DSC thermal analysis illustrates its Tg. The polymers were doped with two types of dopants, iodine and sodium iodide. The electrical conductivity of the doped polymers was measured with three probe cell. The results show increasing in the electrical conductivity with dopant concentration to some levels. The activation energy of the electrical conductivity process was also studied by measuring the electrical conductivity in different temperature. According to the magnitude of the activation energy, we can conclude that the chain flexibility is the dominate factor that influenced on electrical conductivity. Hall Effect and hot probe measurements reveal that the polymer can be considered as $\mathrm{n}$ or $p$ type according to the type of the doping. It was concluded that the doping with iodine produced an n-type while the doping with sodium iodide produced the $\mathrm{p}$ - type.
\end{abstract}

Key words: benzothiazole polymer, doping, hall factor, electrical conductivity.
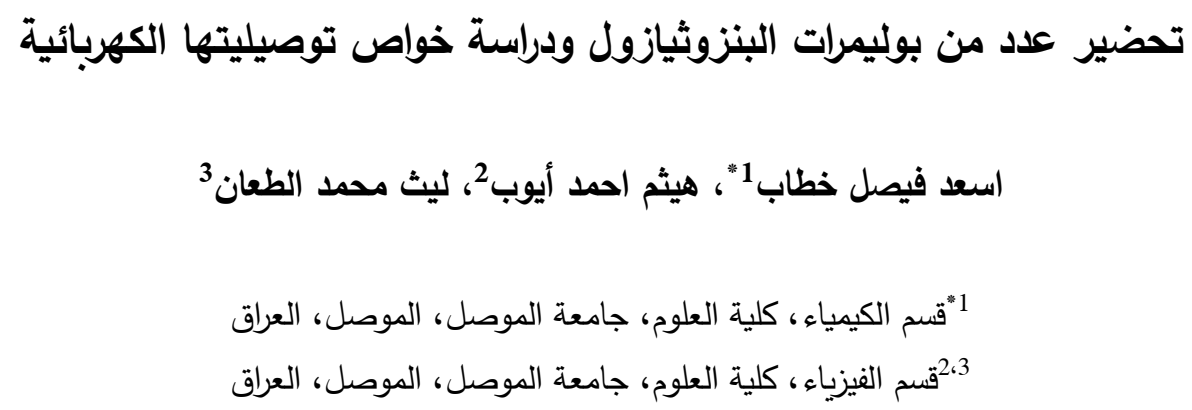

الخلاصة:

عند تشويب البوليمرات المتعاقبة بمشوبات واهبة او مستقبلة فان توصيليتها الكهربائية ستزداد بصورة كبيرة وصلت الى حدودَم

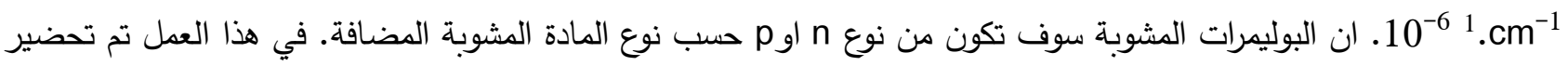
اربعة بوليمرات ضمن سلسلها الرئيسية على مجموعة البنزوثايازول. شخصت مجموعة المونومرات والبوليمرات المحضرة باستخدام 


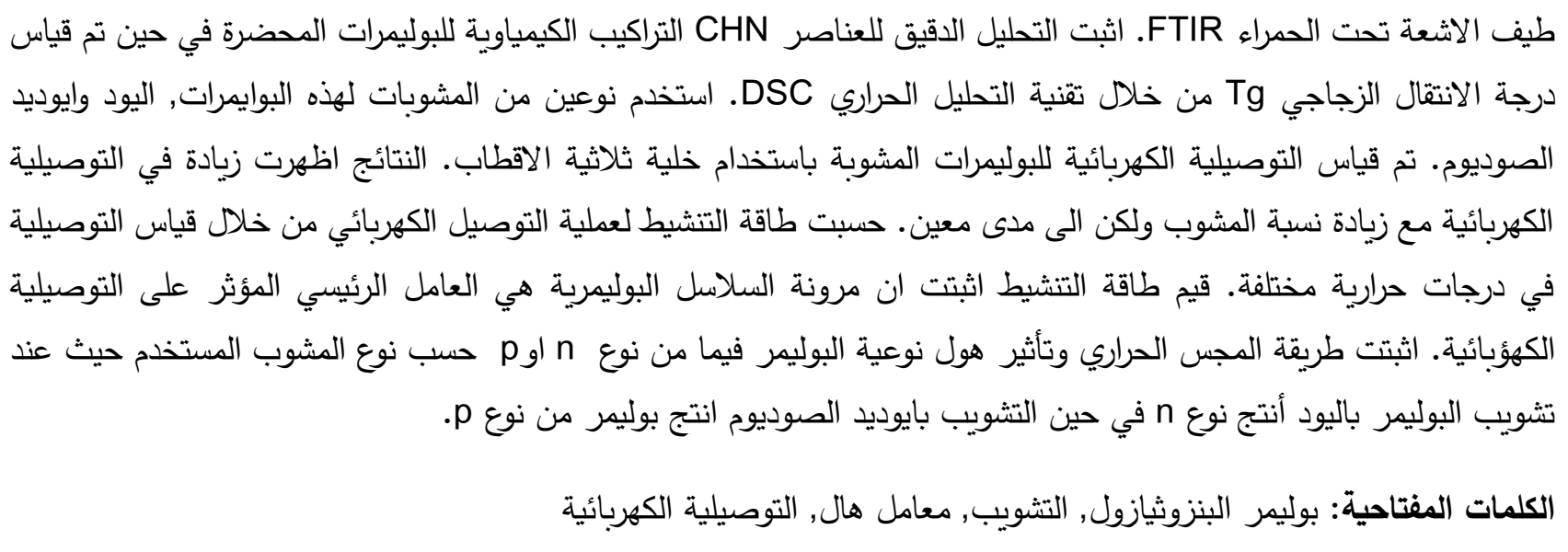

\section{Introduction:}

The field of electrically conducting polymers have been developed very rapidly since the discovery of the intrinsically organic conducting polymers. ${ }^{(1)}$ The electrical conductivity of the organic conjugated polymers was increased by many orders of magnitude when they are doped with oxidizing or reducing agents. ${ }^{(2)}$ Whereby the doped polymers can be seen as a concept of organic metal or semiconductors. The chemical structure of the conjugated polymer is confirmed of $\pi$ electron system extending over long chain of monomer units. ${ }^{(3)}$ The extending $\pi$ system in the conjugated polymer gives the susceptibility of the oxidation and reduction with the electrical conductivity. ${ }^{(4)}$ Through controlling the oxidation and reduction processes, the electrical and optical properties can be systematically varied. ${ }^{(5)}$ The undoped conjugated polymers are established as intrinsic semiconductors. The band gap between HOMO and LUMO energy levels of these polymers depends on the chemical constitution of their backbone and on the nature of the substituents on the main chain. ${ }^{(6)}$ Therefore the electrical and optical properties can be varied to a very large of extended properties by appropriate functionalization of the polymer chains. According to this assumption, many types of conjugated polymers with different backbone constitution and substituents have been prepared. The electrical conductivity of the prepare polymers can be controlled via chemical structure and doping processes controlling, whereby the conductivity arises due to delocalization of the valence electrons through along the conjugated chain ${ }^{(6)}$.

Copolymers based on benzothiadiazole were synthesized since $1961^{(7)}$. It was used to construct high performance electric devices ${ }^{(8)}$. The $\pi$ extended benzothiazole has good planarity and high electron affinity originating from their sulfur atom ${ }^{(9)}$. The solubility problem of the polymer is the main reason in the limitation of their using in many important applications ${ }^{(10)}$. Different long chain aliphatic side groups have been substituted on the main chain on the main chain in order to get solution processable semiconductor polymers ${ }^{(11)}$.

\section{Experimental}

\section{Materials:}

Table (1) shows all the used chemicals which were used as received without any purification except phenylene diamine that was recrystallized from ethanol before using. 
Table 1: Used chemicals

\begin{tabular}{|c|c|c|}
\hline Source & Materials & \\
\hline Fluka & Phenylene diamin & 1 \\
\hline Fluka & Methylene chloride & 2 \\
\hline Fluka & Dibromobutane & 3 \\
\hline BDH & Sodium hydroxide & 4 \\
\hline Sigma Aldrich & Hydrochloric Acid & 5 \\
\hline Scharlau & n-hexane & 6 \\
\hline Fluka & Acetone & 7 \\
\hline BDH & Iodine(I 2$)$ & 8 \\
\hline BDH & Sodium iodide (NaI) & 9 \\
\hline LTD & Dimethyl formamide (DMF) & 10 \\
\hline BDH & Dimethyl sulfoxide (DMSO) & 11 \\
\hline BDH & tetra hydro furan (THF) & 12 \\
\hline Fluka & Pet. Ether 40-60 & 13 \\
\hline Fluka & Ethanol Absolute. & 14 \\
\hline Fluka & Calcium Chloride & 15 \\
\hline BDH & Sulfur & 16 \\
\hline Fluka & Carbon disulfide & 17 \\
\hline
\end{tabular}

\section{Equipment:}

F.T.IR spectra were accomplished by using (BRUKER F.T.IR Infrared Spectrophotometer). The elemental analysis were carried out by using(EuroEA3000/Italy) elemental analyzer. DSC thermal analysis were achieved by using DSC-60 differential scanning calorimeter, SHIMADZU.

\section{Synthetic route:}

\section{2- Mercaptobenothiazole(A1):}

0.025 mole $(2.7 \mathrm{~g})$ of freshly purified phenylene diamine (m.p $140-142^{\circ} \mathrm{C}$ ) was mixed with 0.025 mole $(0.8 \mathrm{~g})$ of sulfur, $2.5 \mathrm{ml}$ abs. ethanol and $1.5 \mathrm{ml}$ of carbon disulfide in an autoclave. The mixture was heated at $180^{\circ} \mathrm{C}$ for a period of $6 \mathrm{hrs}$. After cooling to room temperature, the mixture was dissolved in $10 \mathrm{ml}$ of $10 \%$ sodium hydroxide, filtering, the filtrate was neutralized by $10 \% \mathrm{HCl}$. The precipitate was washed with ethanol and dilute $\mathrm{HCl}$ to get pure brown product (m.p. $245^{\circ} \mathrm{C}$ ).

\section{Thioether for 2- Mercaptobenzothiazole (M1):}


$1.8 \mathrm{~g}$ of A1 was dissolved in $10 \mathrm{ml}$ DMSO. Add $0.4 \mathrm{~g}$ of sodium hydroxide in $10 \mathrm{ml}$ ethanol. Reflux the mixture until a clear homogenous solution with blue green color was obtained. $0.3 \mathrm{ml}$ of methylene chloride $\left(\mathrm{CH}_{2} \mathrm{Cl}_{2}\right)$ was added dropwise to the clear solution with continuous reflux for a period of $2 \mathrm{hrs}$. The color was changed to a deep yellow. After cooling the solution, $50 \mathrm{ml}$ of cold water was added. The precipitated M1 was filtered washed with water and dry under vacuum.

\section{Thioether for 2- Mercaptobenzothiazole (M21):}

The same procedure was followed for the preparation of $\mathrm{M} 2$ by the reaction of $\mathrm{A} 1$ with 1,4dibromobutane $\mathrm{Br}\left(\mathrm{CH}_{2}\right)_{4} \mathrm{Br}$.

\section{2,2 $\sim$-bis Mercaptobenothiazole(A2):}

The same procedure was used in preparing of A1 with exception of duplicating the amount of sulfur and carbon disulfide. The product is yellow and has a melting point of $253^{\circ} \mathrm{C}$

\section{Terephthaloyl dichloride:}

$4 \mathrm{~g}$ of terephthalic acid was refluxed with $30 \mathrm{ml}$ thionyl chloride in presence of some drops of DMF for a period of $1 \mathrm{hr}$., distill the excess thionyl chloride, the residual Terephthaloyl chloride was recrystallized from $n$ - hexane.

\section{Polymer synthesis:}

\section{Polyamide of $M 1$ and $M 2$ \{P1 \& P2\}:}

0.01 mole of the monomer terephthaloyl dichloride was dissolved in $10 \mathrm{ml}$ dry dichloromethane and introduced in three necked flask provided with nitrogen inlet tube. 0.01 mole of monomer M1 or M2 was dissolved in $10 \mathrm{ml}$ of 1:1 THF/pyridine mixed solvent and dripped slowly into the reaction flask under nitrogen atmosphere. The reaction mixture was stirred for $24 \mathrm{hr}$. at room temperature. The precipitated polymer was poured into fivefold of methanol, filtered and dried under vacuum.

\section{Polymerization of A2 \{P3\&P4\}:}

P3 polymer was prepared by dissolving $1.2 \mathrm{~g}$ of A2 in appropriate amount of DMSO. $0.4 \mathrm{~g}$ of sodium hydroxide dissolved in absolute methanol was added; the mixture was heated to about $80^{\circ}$, and then $0.23 \mathrm{ml}$ of methylene chloride was added to it. The whole mixture was heated for about $3 \mathrm{hrs}$. The produced polymer was precipitated from water, filtered, washed with water and dried under vacuum. P4 polymer was prepared by polymerizing A2 with dibromobutane by following the above method whereby $0.5 \mathrm{ml}$ of dibromobutane reacts with $1.2 \mathrm{~g}$ of A2.

\section{Doping of polymers:}

Two types of doping processes are achieved in this work; the first type is doping by mixing whereby the polymers were mixed thoroughly with different ratios of the dopant sodium iodide NaI. The second type of doping is the vapor-phase doping in which the polymer disc has been exposed to the vapor of the iodine in vacuum tube for different periods of time.

\section{Two-Prop method for evaluation the type of charge carriers in doped polymer: ${ }^{(12)}$}

Two probes (hot and cold) were used in order to identify the charge carriers type ( p-type or n- type). The sharp ends of the probes are attached to the surface of the polymer disc while the second ends are connected to galvanometer as in figure (1). If the polymer is n-type, the liberated electron accumulates 
at the hot probe and the galvanometer pointed to negative side, while in the case of the p-type, the galvanometer pointed to positive side. The results were confirmed by measuring Hall factor ${ }^{(13)}$

Figure 1: The two-prop method

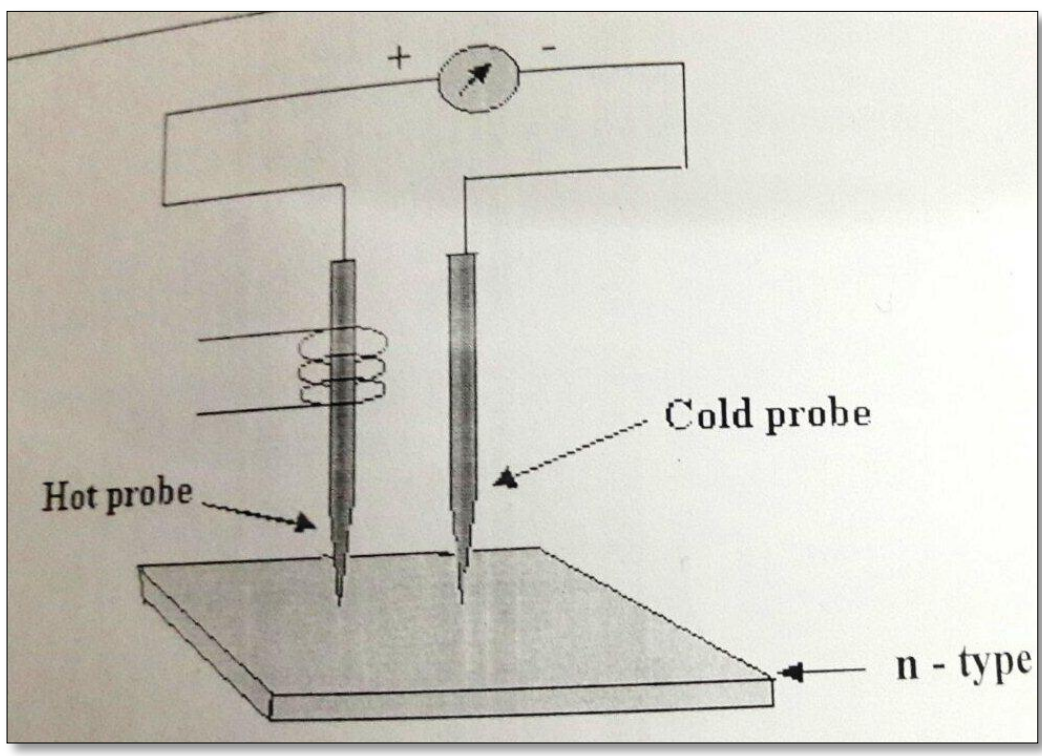

\section{Electrical conductivity measurements:}

Films of $2 \mathrm{~cm}$ diameter and about $0.5 \mathrm{~mm}$ thickness from the pure polymers are prepared under 3-4 ton $/ \mathrm{cm}^{2}$. Electrical volume conductivity measurements are performed using the standard 3-probe D.C technique according to the ASTM method ${ }^{(14)}$.

\section{Results and Discussions}

\section{Synthetic routs:}

\section{Monomer preparation:}

Scheme (1) illustrated the synthetic route for the preparation of monomers. The properties of the monomers are illustrated in table (2).

Table 2: Properties and chemical structure of the prepared monomers

\begin{tabular}{|c|c|c|c|c|c|c|c|}
\hline Sample & $\begin{array}{c}\mathrm{v} \mathrm{N}-\mathrm{H} \\
\mathrm{cm}^{-1}\end{array}$ & $\begin{array}{c}\sigma \mathrm{N}-\mathrm{H} \\
\mathrm{cm}^{-1}\end{array}$ & $\begin{array}{l}\text { Aliphatic } \\
\mathrm{C}-\mathrm{H} \mathrm{cm}^{-1}\end{array}$ & $\begin{array}{c}v \mathrm{C}=\mathrm{N} \\
\mathrm{cm}^{-1}\end{array}$ & $\begin{array}{c}\text { v C }=\mathrm{C} \\
\mathrm{cm}^{-1}\end{array}$ & $\begin{array}{l}\text { v C-S } \\
\text { cm-1 }\end{array}$ & $\begin{array}{c}\text { v S-H } \\
\mathrm{cm}^{-1}\end{array}$ \\
\hline M1 & 3248 & 1619 & 2957-2910 & 1313 & 1510 & 828 & ---.-- \\
\hline M2 & 3241 & 1607 & 2916-2810 & 1307 & 1508 & 824 & \\
\hline A2 & ------- & -----------. & ----------- & 1418 & 1535 & 850 & 3255 \\
\hline
\end{tabular}


Scheme (1): Monomers prepared from p-phenylene diamine

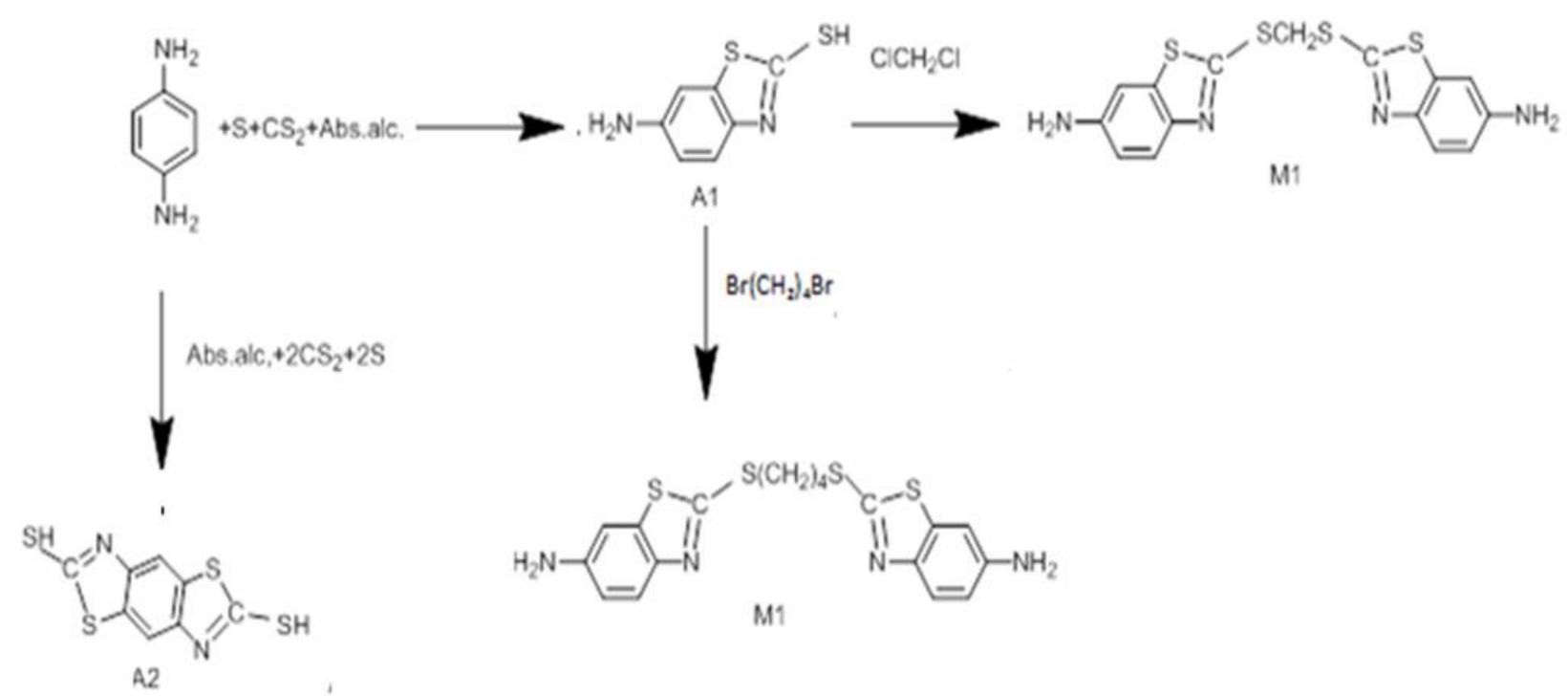

The monomers were characterized by IR spectroscopy (figures $2,3 \& 4$ ). The frequency of the bands belongs to the different functional groups of the synthesized monomers that are shown in table (3).

Table 3: FTIR band absorption frequencies of the functional groups of the prepared monomers

\begin{tabular}{|c|c|c|c|}
\hline monomer & Chemical structure & color & m.p. $/{ }^{\circ} \mathrm{C}$ \\
\hline M1 & & brown & 280 \\
\hline M2 & & brown & 265 \\
\hline A2 & & orang & 273 \\
\hline
\end{tabular}




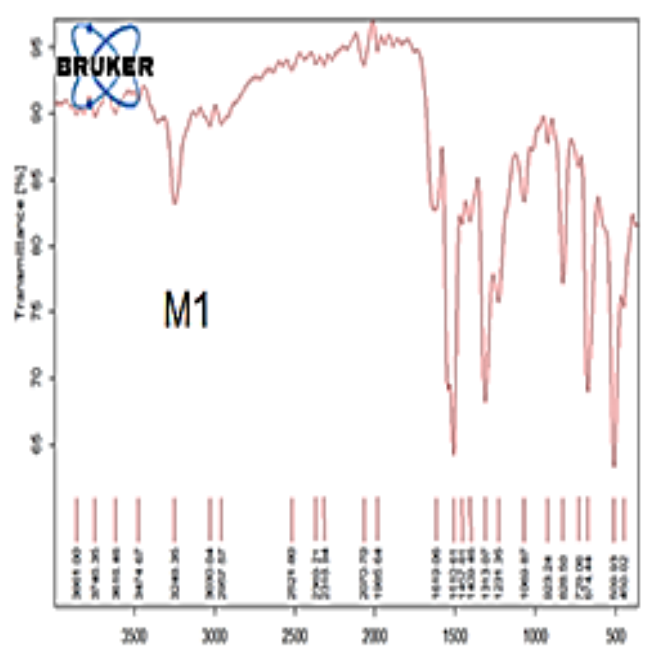

figure(2): IR spectrum of monomer M1

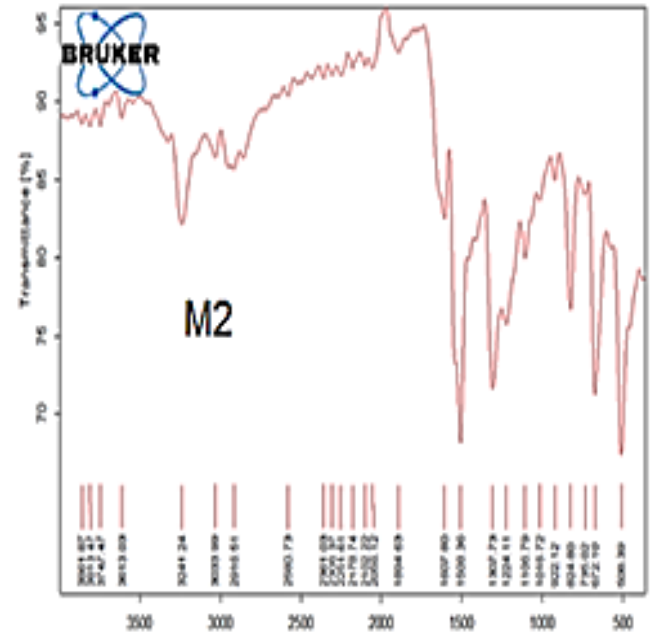

figure(3):IR spectrum of monomer M2

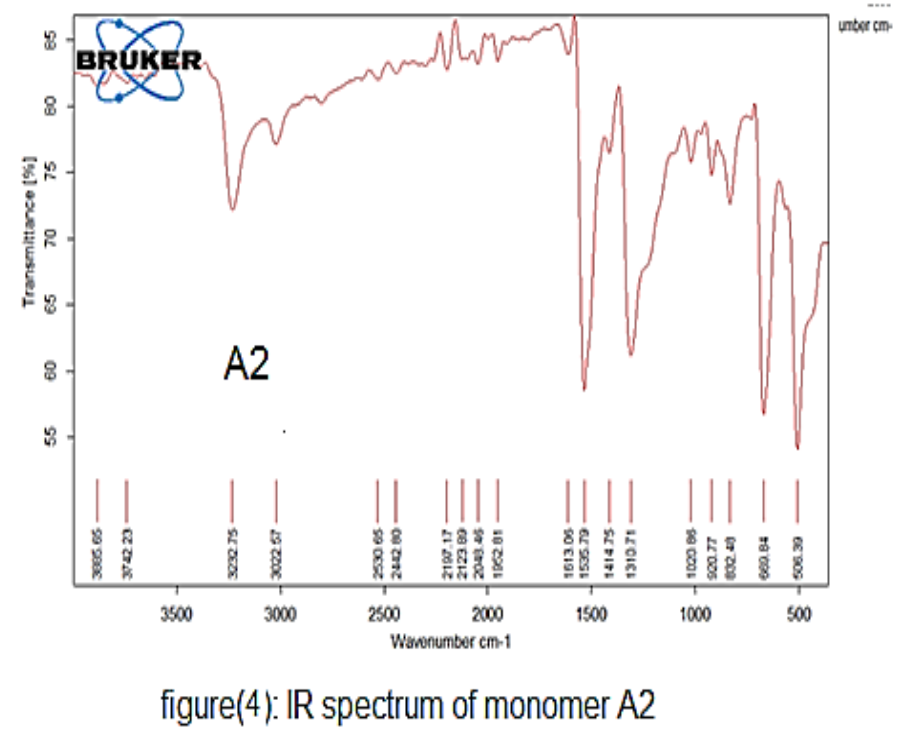

\section{Synthesis of Polymers:}

The four prepared polymers are specialized with benzothiazole moiety within their backbone. Scheme 2 illustrates the equations of the preparation of the polymers. 

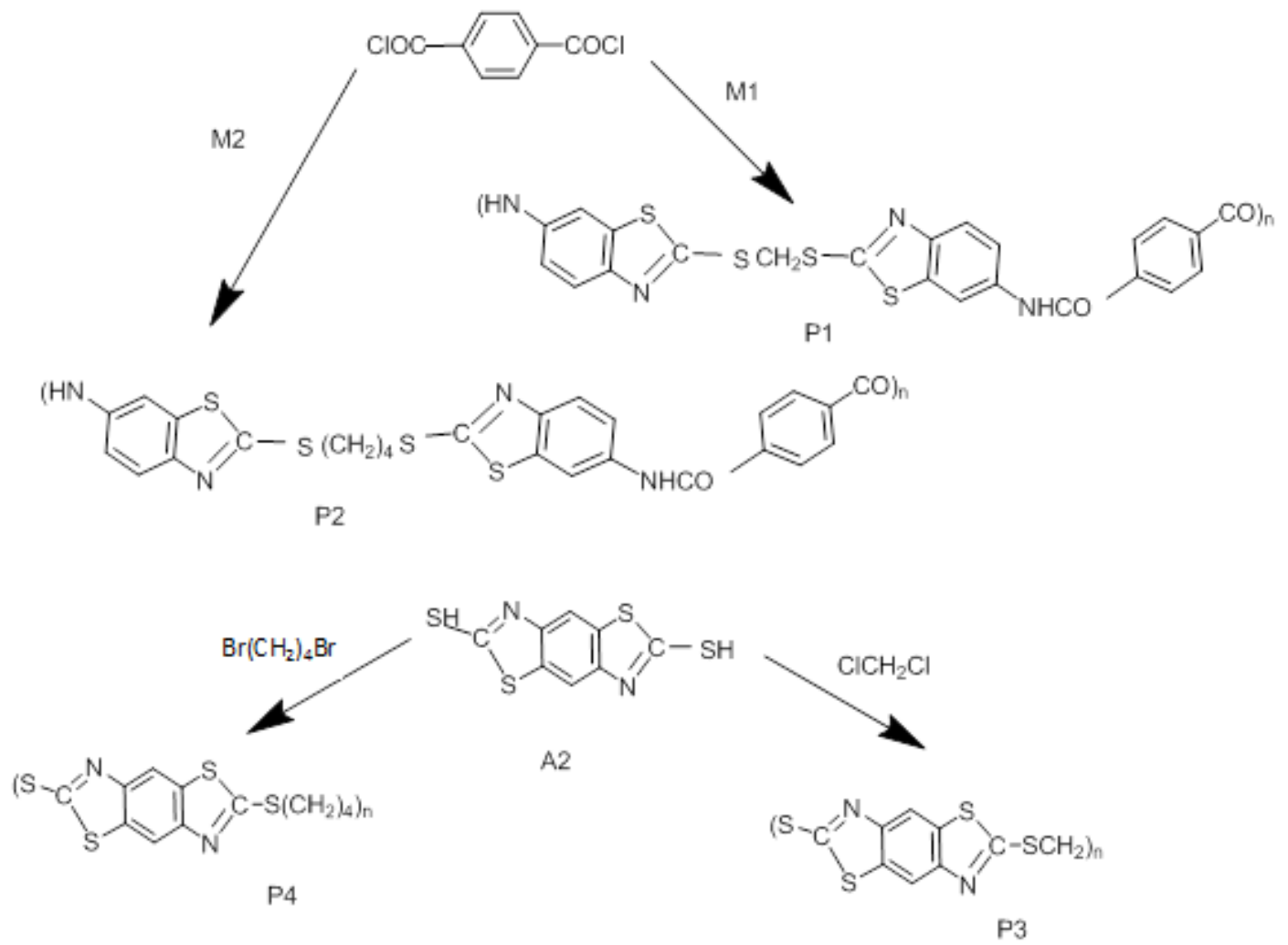

Scheme(2): route of polymer synthesis

The polymers were characterized by IR spectroscopy figure(5). Table (4) gives the frequencies of the special function groups within the polymer chains. In comparison with the spectrum of the related monomers, it was noticed that the frequency of NH moiety in monomers M1\&M2 has been disappeared and a new signal was observed at about $1680 \mathrm{~cm}^{-1}$ related to the carbonyl group to confirm the formation of the polymers M1and M2. While figure(4) indicates the disappearance of SH group which give signal at $3255 \mathrm{~cm}^{-1}$ in monomer and a new frequency has appeared around $3000 \mathrm{~cm}^{-1}$ related to the aliphatic moieties.

Table 4: FTIR band frequencies of the prepared polymers

\begin{tabular}{|c|c|c|c|c|c|c|c|}
\hline No. & $\begin{array}{c}\text { v N-H } \\
\text { cm }^{-1}\end{array}$ & $\begin{array}{c}\sigma \mathrm{N}-\mathrm{H} \\
\mathrm{cm}^{-1}\end{array}$ & $\begin{array}{l}\text { Aliphatic } \\
\text { C-H Cm-1 }\end{array}$ & $\begin{array}{c}v \mathbf{v}=\mathbf{N} \\
\mathbf{c m}^{-1}\end{array}$ & $\begin{array}{c}\text { v } \mathrm{C}=\mathrm{C} \\
\mathrm{cm}^{-1}\end{array}$ & $\begin{array}{l}\text { v C-S } \\
\text { cm }^{-1}\end{array}$ & $\begin{array}{c}v \mathrm{C}=\mathbf{O} \\
\mathrm{cm}\end{array}$ \\
\hline P1 & 3241 & 1650 & $2992-2816$ & 1413 & 1503.7 & 828 & 1680 \\
\hline P2 & 3285 & 1682 & $3058-2820$ & 1411 & 1503.5 & 829 & 1783 \\
\hline P3 & ----- & 1638 & $3037-2950$ & 1399.34 & 1510 & 829 & ----- \\
\hline P4 & ----- & 1603 & $3044-2960$ & 1404 & 1504 & 828 & ----- \\
\hline
\end{tabular}



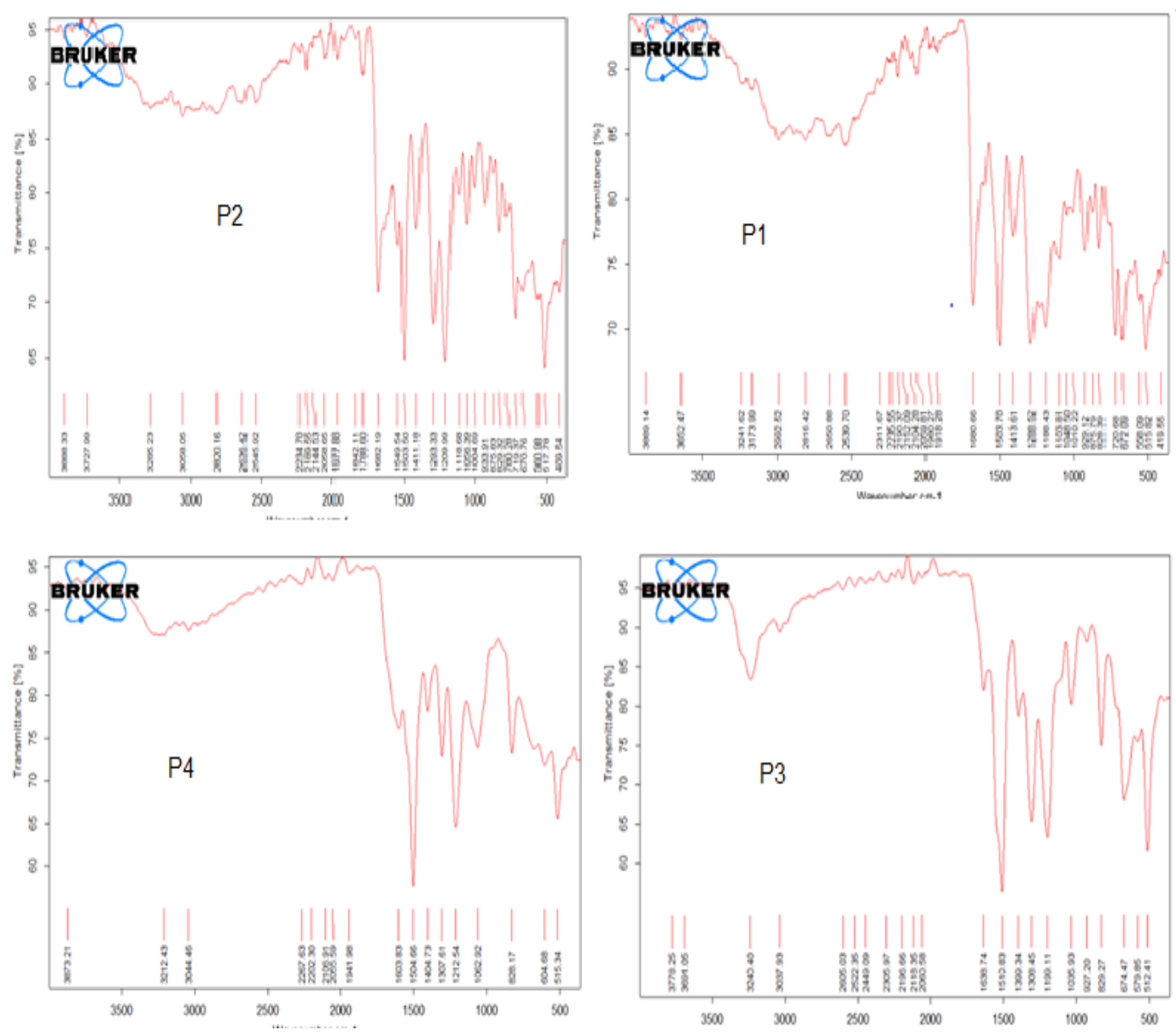

Figure(5): FTIR spectrum of the prepared polymers

The fine elemental analysis ( $\mathrm{CHN}$ ) of the prepared polymers (table 5) demonstrate the suggested chemical structure of the prepared polymers.

Table 5: CHN elemental analysis of the undoped polymers

\begin{tabular}{|c|c|c|c|c|c|c|}
\hline \multirow{2}{*}{ Polymer } & \multicolumn{2}{|c|}{ \% C } & \multicolumn{2}{c|}{ \% H } & \multicolumn{2}{c|}{ \% N } \\
\cline { 2 - 7 } & Calc. & Exp. & Calc. & Exp. & Calc. & Exp. \\
\hline P1 & 56.93 & 57.83 & 10.21 & 10.45 & 3.65 & 3.66 \\
\hline P2 & 54.54 & 55.29 & 11.06 & 11.87 & 2.76 & 2.94 \\
\hline P3 & 40.29 & 40,83 & 10.44 & 10.18 & 1.49 & 1.89 \\
\hline P4 & 46.45 & 47.08 & 9.03 & 9.132 & 3.22 & 3.31 \\
\hline
\end{tabular}

\section{Thermal analysis of the polymers:}

The thermal DSC scans of the prepared polymers are shown in figure 6 . The results demonstrated that the polymer P3 and P4 have shown glass transition temperature between $142-183^{\circ} \mathrm{C}$ and 135 - 
$168^{\circ} \mathrm{C}$ respectively. The high rigid polymers $\mathrm{P} 1$ and $\mathrm{P} 2$ have glass transition temperature ranged 283$320^{\circ} \mathrm{C}$ and $233-253^{\circ} \mathrm{C}$ respectively. The results can be explained by that the polymers P1and $\mathrm{P} 2$ can be considered as a copolymers of amide and thioether, while the polymers P3 and P4 are homo thioether polymers more flexible than polymers P1 and P2. The amide moiety gives the polymer a hardness properties by their hydrogen bonding.
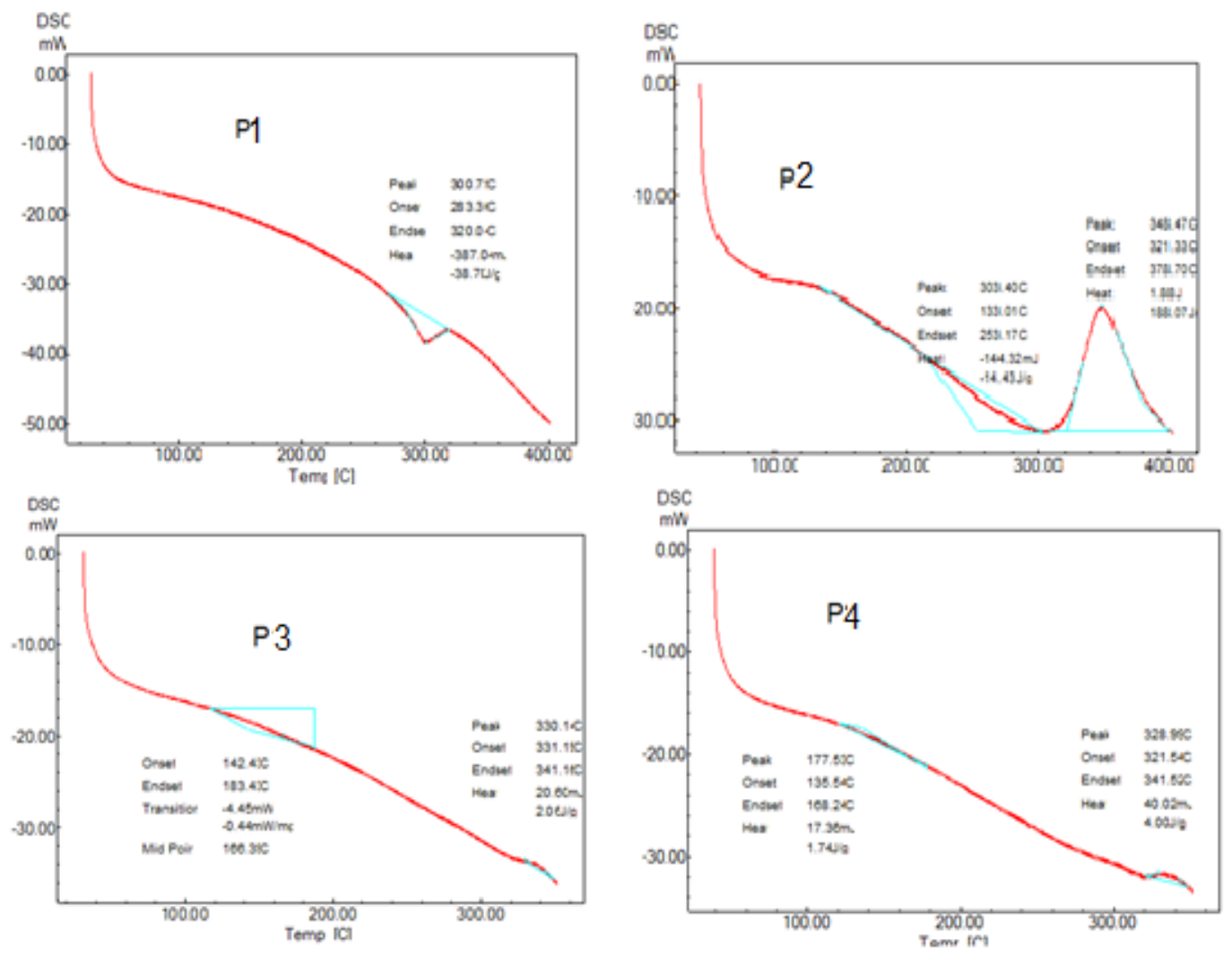

Figure 6: DSC scans of the prepared polymers

\section{Electrical conductivity measurements: doping processes:}

The electrical conductivity of the conjugated polymers can be enhanced by doping with some donor or acceptor dopants. The values of the volume electrical conductivity of the investigated doped polymers are shown in tables $(6 \& 7)$ and figures $(7 \& 8)$. Generally it was clearly noticed that the conductivity increased systematically with increasing the dopant ratio. The data shows that after reaching some ratio of doping, the conductivity stop increasing or decrease, whereby at this point of doping the percolation point was reached. After the percolation point the dopant may start building some crystal units within the polymer chains and decrease the conductivity ${ }^{(15)}$. 
Table 6: Room temperature electrical conductivity $\sigma\left(\Omega . \mathrm{cm} \times 10^{-8}\right)$ of polymers doped with different ratio of iodine.

\begin{tabular}{|c|c|c|c|c|c|c|c|c|c|c|}
\hline Polymer & $\boldsymbol{\%}$ & $\boldsymbol{\sigma}$ & $\boldsymbol{\%}$ & $\boldsymbol{\sigma}$ & $\boldsymbol{\%}$ & $\boldsymbol{\sigma}$ & $\boldsymbol{\%}$ & $\boldsymbol{\sigma}$ & $\boldsymbol{\%}$ & $\boldsymbol{\sigma}$ \\
\hline P1 & 5 & 1.25 & 10 & 7.67 & 15 & 8.69 & 17 & 9.16 & 20 & 8.82 \\
\hline P2 & 3 & 1.26 & 10 & 10.54 & & & & & 20 & 10.6 \\
\hline P3 & 7 & 6.65 & 11 & 8.84 & & & & & 25 & 9.2 \\
\hline P4 & 2 & 1.6 & 4 & 3.6 & 7 & 6.8 & 8 & 7.6 & 10 & 4.9 \\
\hline
\end{tabular}

Table 7: Room temperature electrical conductivity $\sigma\left(\Omega \cdot \mathrm{cm} \times 10^{-8}\right)$ of polymers doped with different ratio of sodium iodide.

\begin{tabular}{|c|c|c|c|c|c|c|c|c|c|c|c|c|}
\hline p & $\boldsymbol{\%}$ & $\boldsymbol{\sigma}$ & $\boldsymbol{\%}$ & $\boldsymbol{\sigma}$ & $\boldsymbol{\%}$ & $\boldsymbol{\sigma}$ & $\boldsymbol{\%}$ & $\boldsymbol{\sigma}$ & $\boldsymbol{\%}$ & $\boldsymbol{\sigma}$ & $\boldsymbol{\%}$ & $\boldsymbol{\sigma}$ \\
\hline P1 & 2 & 6.8 & 4 & 8.2 & 5 & 8.8 & 7.5 & 9.3 & 11 & 9.2 & 14 & 8.8 \\
\hline P2 & 2.5 & 8.5 & 7 & 9.5 & 10 & 10.2 & 14.5 & 10.5 & 17.5 & 10.7 & 20 & 10.4 \\
\hline P3 & 2 & 5.6 & 3 & 7.4 & 5 & 7.9 & 6.5 & 8.9 & 9.5 & 8.85 & 14 & 8.2 \\
\hline P4 & 1.5 & 2.1 & 3 & 6.6 & 4 & 7.2 & 8 & 7.8 & 10.5 & 9.2 & 17 & 9.3 \\
\hline
\end{tabular}

It was clearly noticed that there are many factors that have effects on the electrical conductivity of the polymers. The polymer chain constituents is the main factor. Interruption of the polymer chin with aliphatic moieties may have two different effects, increasing the flexibility of the chain or decreasing the delocalization of the $\pi$ electrons along the chain. The first factor increases the conductivity while the second, decrease the conductivity ${ }^{(16)}$. The first factor was observed in a comparison made between P1 \& P2 doped with iodine or NaI. While the latter factor was dominated in a comparison between P3\&P4 doped with NaI.

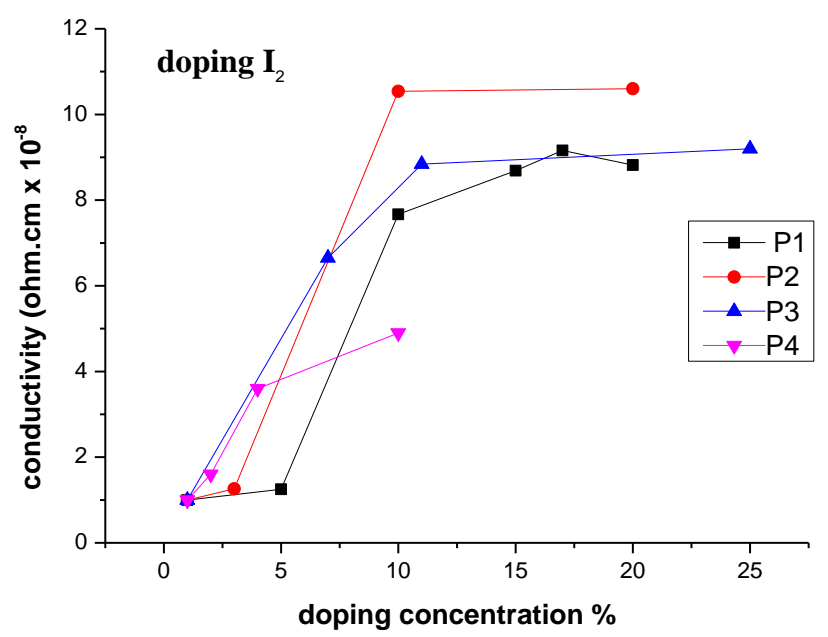

Figure 7: The conductivity of p-type polymer vs. the doping concentration of $I_{2}$ 


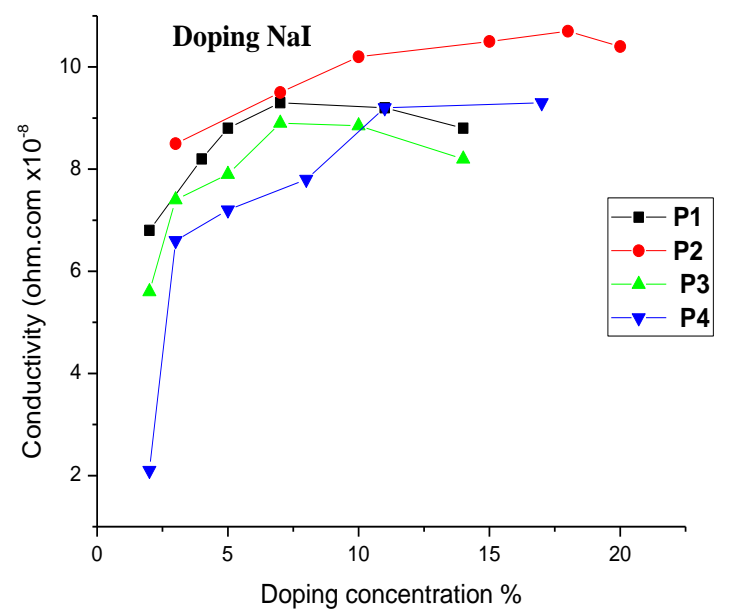

Figure 8: The conductivity of n-type polymer vs. the doping concentration of NaI

Types of dopants: Two types of dopant were carried out for all the prepared polymers. The first used dopant is iodine which is known as electron donor. The second dopant is sodium iodide, whereby the sodium ion can be considered as an electron acceptor. The resulted polymers are n-type and p-type respectively. Hot and Cold Probe Test proved that iodine doped polymers are of n- type while sodium iodide doped polymers are of p-type. The results were experimentally proved by measuring the Hall coefficient $\mathrm{R}_{\mathrm{H}}$ from ${ }^{(17)}: \mu=\mathrm{R}_{\mathrm{H}} \sigma$, where $\mu$ is the mobility of the carriers of (e and $\mathrm{h}$ ) and $\sigma$ is the conductivity of the polymer.

Table 8: Hall coefficient $\left(R_{H}\right)$, the mobility $(\mu)$ and the conductivity $(\sigma)$ of the doped polymers

\begin{tabular}{|c|c|c|c|c|c|c|}
\hline sample & $\begin{array}{c}\sigma \\
(\Omega . c m)^{-1} \\
10 \% I_{2} \\
\text { doping } \\
\end{array}$ & $\underset{\left(\mathrm{cm}^{2} . \mathrm{vs}\right)}{\mu}$ & $\begin{array}{c}\mathbf{R}_{\mathbf{H}} \\
\left(\mathrm{cm}^{3} / \mathrm{c}\right) \\
{[\text { p-type] }}\end{array}$ & $\begin{array}{c}\sigma \\
\left(\Omega . \mathrm{cm}^{-1}\right) \\
10 \% \mathrm{NaI} \\
\text { doping }\end{array}$ & $\underset{\left(\mathrm{cm}^{2} . \mathbf{v s}\right)}{\mu}$ & $\begin{array}{c}\mathbf{R}_{H} \\
\left(\mathrm{~cm}^{3} / \mathrm{c}\right) \\
{[\mathrm{n}-\mathrm{type}]}\end{array}$ \\
\hline P1 & $1.40 \times 10^{-6}$ & 64.46 & $4.59 \times 10^{+7}$ & $1.65 \times 10^{-6}$ & 56.13 & $-3.38 \times 10^{+7}$ \\
\hline $\mathbf{P 2}$ & $3.63 \times 10^{-6}$ & 135.6 & $3.73 \times 10^{+7}$ & $2.07 \times 10^{-6}$ & 157.4 & $-7.57 \times 10^{+7}$ \\
\hline P3 & $2.59 \times 10^{-6}$ & 5,16 & $1.9 \times 10^{+7}$ & $2.03 \times 10^{-6}$ & 51.4 & $-2.52 \times 10^{+7}$ \\
\hline P4 & $1.51 \times 10^{-7}$ & 0.319 & $2.11 \times 10^{+7}$ & $1.54 \times 10^{-6}$ & 25.3 & $-1.6 \times 10^{+7}$ \\
\hline
\end{tabular}

\section{Temperature effect:}

Increasing electrical conductivity with elevation in temperature can be considered by calculating the activation energy of this process. The explanation is established by a gradual rise in the population of electrons in conduction bands (excited state) ${ }^{(18)}$, which needs activation energy between 1.5- 2 Ev.mol ${ }^{-1}$. In the other hand the increasing in the flexibility of the polymeric chains and electrical conductivity with temperature elevation gives lower activation energy ${ }^{(19)}$. Table (9) shows the activation energies of the doped polymers with sodium iodide. The low value of activation energy demonstrates the lower level of sensitivity of the electrical conductivity to temperature. According to this activation energy magnitude we can say that the chain flexibility is the dominate factor in explaining the conductivity mechanism. 
Table 9: Activation energy $(\Delta \mathrm{E})$ of the prepared polymers measured between $(25-250)^{\circ} \mathrm{C}$

\begin{tabular}{|c|c|c|c|c|}
\hline Polymer & P1 & $\mathbf{P 2}$ & P3 & P4 \\
\hline$\Delta \mathrm{E} / \mathrm{eV} \cdot \mathrm{mol}^{-1}$ & 0.0303 & 0.0302 & 0.0148 & 0.0346 \\
\hline
\end{tabular}

\section{Conclusions:}

The electrical conductivity is a significant characteristic of polymers, according to which the polymers are guided to be used. It was seen that the chemical structure of the polymer is the main factor to give the polymers their physical properties and controlling the electrical conductivity. The electrical conductivity can be enhanced by doping with electron donor or acceptor dopants. The same polymer can be used an n- or p-type by using electron donor or acceptor dopants.

Acknowledgements: The authors wish to thank the collage of material engineering/Babylon university for their helps in measuring the electrical, thermal properties and IR spectroscopy. Special thanks to Prof. Mohammed H. Al Maamori and Dr. Mohammed Hadi Shinen for their technical information and helping in guiding the project.

\section{References:}

1- Shirakawa H., Louis E. J., MacDiarmid A. G., Chaing C. K. and Heeger A. H., J.C.S. Chem. Comun. Physical Rev., 578 (1977).

2- Shirakawa H. and Kobayashi T., J. Phys. Paris, C3, 3(1983)

3- Chaing C.K., Finchec C. R., Park Y. W., Heeger A. J., Lewis E. J., Chan S. C. and MacDiarmid A. J., Phys. Rev. Lett., 39,1098 (1977).

4- Barford W., International series of monographs on physics,129, Electronic and optical properties of conjugated polymers, Oxford University press Inc. New York (2005).

5- MacDiarmid. A. G., "Synthetic Metals": A Novel Role for Organic Polymers, (Nobel Lecture), Angrew, Chem. Int. Ed., 40 2581-2590, (2001)

6- Mishra A. K., Atomic J., Molecular, Condensate and Nano physics, 5,159 (2018).

7- Van Mullekom H. A. M., Venkemans H.A.J. M. and Meijer E. W., chem. Commun., 2163 (1991).

8- Chen H. and Cao Y., Acc. Chem. Res., 42.1709 (2009).

9- Banal L., Subbiah J., Graham H., Lee J. K., Ghiggino K. P. and Wong W.W., Polym. Chem., 4, 1077, (2013).

10- Kono T., Kumaki D., Nishida J., Tokito S. and Y Yamashita., Chem. Comumun., 46, 3265 (2010).

11- Tam T. I., Li H., Wei F., Tan K. H., Kloc C., Lam Y.M., Mhaisalkar S. G. and Grimsdale A. C., Org. Lett., 12, 3340 (2010).

12- Saeed N. and Suhail A., "Enhancement the Optical Properties of Zinc Sulfide Thin Films for Solar Cell Applications", Iraqi Journal of Science, Vol.53, No.1, (2012).

13- -Raymond A. Serway, "Physics for Scientists and Engineers", Emeritus, James Madison University John W. Jewett - California State Polytechnic University, Pomona Thomson Brooks/Cole (C) 6th Edition. (2004).

14- ASTM, Annual Book of standards, D.C. Resistance or conductivity of insulating materials D527, part 39. Philadelphia: American society of testing and materials, 1981.

15- Khattab A.F., Mahmood S. F. and Shahab Y.A., Optoelectron J., Adv. Mat., 10, 1463 (2008).

16- Khattab A. F. and AL-Chalabi R. M.A., Tikrit Journal of Pure Science 18 (3) (2013). 
17- Danial D., Harry E., "Deposision of Cu in AlSe 2 films", Apply physics lett.,vol.80,No.7, pp137143 (1997).

18- Serin M., Sakar D. and Canlcuttaran O., J. Optoelectron. Adv. Mat. ,6(1), 238 (2004).

19- AL- Shawabkeh A. F., AL- Wahab H. A. and Shahab Y. A., J. Optoelectron. Adv. Mat., 9 (7), 2075 (2007). 